\title{
LANL/Green Star Tests of the Green Star SBS-60 Spectrometer
}

\section{Los Alamos \\ NATIONAL LABORATORY}

Los Alamos National Laboratory is operated by the University of California for the United States Department of Energy under contract W-7405-ENG-36. 
An Affirmative Action/Equal Opportunity Employer

This report was prepared as an account of work sponsored by an agency of the United States Government. Neither The Regents of the University of California, the United States Government nor any agency thereof, nor any of their employees, makes any warranty, express or implied, or assumes any legal liability or responsibility for the accuracy, completeness, or usefulness of any information, apparatus, product, or process disclosed, or represents that its use would not infringe privately owned rights. Reference herein to any specific commercial product, process, or service by trade name, trademark, manufacturer, or otherwise, does not necessarily constitute or imply its endorsement, recommendation, or favoring by The Regents of the University of California, the United States Government, or any agency thereof. The views and opinions of authors expressed herein do not necessarily state or reflect those of The Regents of the University of California, the United States Government, or any agency thereof. Los Alamos National Laboratory strongly supports academic freedom and a researcher's right to publish; as an institution, however, the Laboratory does not endorse the viewpoint of a publication or guarantee its technical correctness. 


\title{
LANL/Green Star Tests of the
}

Green Star SBS-60 Spectrometer

\author{
T. E. Sampson \\ D. T. Vo \\ T. L. Cremers \\ P. A. Hypes \\ Y.P. Seldiakov* \\ A. B. Dorin* \\ M. V. Kondrashov* \\ V.I. Timoshin ${ }^{* *}$
}




\section{CONTENTS}

ABSTRACT [............................................................................. 1

I. INTRODUCTION ............................................................. 2

II. LOS ALAMOS DATA ACQUISITION SYSTEM

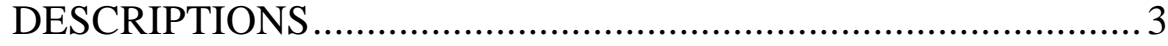

III. GREEN STAR DATA ACQUISITION SYSTEM SETUP ............. 3

IV. DATA ACQUISITION AND ANALYSIS ..............................6

V. RESOLUTION AND THROUGHPUT MEASUREMENTS .......... 7

VI. DISCUSSION OF RESOLUTION, THROUGHPUT AND COUNT RATE STABILITY MEASUREMENTS ....................... 10

VII. INTEGRAL NONLINEARITY TESTS................................... 10

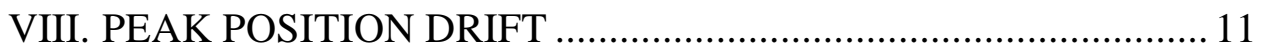

IX. PLUTONIUM ISOTOPIC ANALYSIS RESULTS ..................... 12

X. HIGH ENERGY “SHIELDED” ANALYSIS, 200-800 keV .......... 18

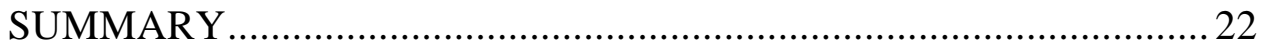

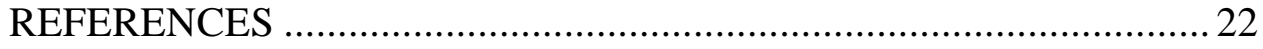




\title{
LANL/GREEN STAR TESTS OF THE GREEN STAR SBS-60 SPECTROMETER
}

\author{
by \\ T. E. Sampson, D. T. Vo, T. L. Cremers, P. A. Hypes, \\ Y. P. Seldiakov, A. B. Dorin, M. V. Kondrashov, \\ and V. I. Timoshin
}

\begin{abstract}
We report on joint testing of the Russian-designed and manufactured single board spectrometer SBS-60 from Green Star Ltd. of Moscow. The SBS-60 will be used to make material control and accountability measurements on plutonium in the Russian plutonium disposition program.

We compared three SBS-60 units of two different designs with three commonly used commercial US data acquisition systems by making measurements with three different HPGe detector systems. The measurements were performed to test if the gamma-ray spectral data of plutonium samples from the SBS-60 was suitable for analysis for the isotopic composition of plutonium using the Los Alamos FRAM $^{*}$ isotopic analysis software. Each detector fed its signal to two data acquisition systems, one SBS-60 and one commercial US system. The data from the two systems were analyzed by FRAM and compared. In addition, we characterized the throughput, resolution, and stability of the SBS-60 data acquisition system in comparison with the commercial US systems. This report presents detailed results of all the tests performed.
\end{abstract}

\footnotetext{
* The name for the Los Alamos-developed plutonium isotopic analysis software FRAM is a Scandanavian word meaning "forward" or "onward."
} 


\section{INTRODUCTION}

The United States and Russia have agreed to the joint development of a nondestructive assay system (NDA) to support the conversion of plutonium metal from dismantled Russian nuclear weapons to plutonium oxide for use in mixed oxide (MOX) reactor fuel. The NDA system for Russia will be functionally patterned after the ARIES (Advanced Recovery and Integrated Extraction System) NDA system in operation at Los Alamos National Laboratory (LANL). One goal of the program is to produce an NDA system for use in Russia that maximizes the use of Russian resources to facilitate maintenance and future upgrades.

LANL and Green Star jointly tested the Green Star SBS-50 single board spectrometer system (Green Star Ltd., Moscow, Russia) in 1997. ${ }^{1}$ The testing was directed at the possible use of the SBS-50 as a data acquisition system for isotopic analysis applications with the LANL FRAM ${ }^{2,3}$ gamma-ray isotopic analysis software. One of the recommendations from the 1997 testing was that Green Star proceed with the development of the SBS-60 spectrometer with a faster analogto-digital converter (ADC) to improve throughput. This report describes the testing of this improved spectrometer board, the SBS-60. The overall purpose of the testing was to evaluate the SBS-60 spectrometer as a data acquisition device for use with the LANL FRAM isotopic analysis software.

The tests reported here are similar to those reported in Ref. 1.

1. Test performance of Green Star spectrometer with respect to resolution and throughput. Perform tests as a function of counting rate using both planar and coaxial detectors.

2. Test the Green Star spectrometer as a front end data acquisition device for use with the LANL FRAM software.

The testing of the SBS-60 included some additional tests not performed in 1997, including integral linearity and peak position stability. The isotopic measurements with plutonium samples were less extensive than those carried out in 1997.

The testing described in this report took place in a three day period between noon on October 12 and noon on October 15, 1999, at LANL. 


\section{LOS ALAMOS DATA ACQUISITION SYSTEM DESCRIPTIONS}

We used three different Los Alamos detector/data acquisition systems to collect data in parallel with three SBS-60 systems.

1. LANL planar HPGe detector system "Planar detector"

ORTEC Model SGD-25520-S, SN: 39-N21194D, $25 \mathrm{~mm}$ dia by $15 \mathrm{~mm}$ thick

This detector suffered a high-voltage failure part way through the testing. The remainder of the planar detector testing was conducted with Canberra Model GL0213S, SN: 11892067 , $16 \mathrm{~mm}$ diam by $15 \mathrm{~mm}$ thick.

LANL Data Acquisition System with Planar HPGe Detector System "NIM" System"

ORTEC 4001C/4002D NIM Bin and Power Supply

Canberra 3106D High Voltage Bias Supply

ORTEC 672 Spectroscopy Amplifier

Canberra $8706450 \mathrm{MHz}$ ADC

Canberra 8233 Digital Stabilizer

ORTEC 996 Timer and Counter

ORTEC MatchMaker EtherNIM Multichannel Analyzer

IBM 760XD Think Pad Computer

2. LANL ORTEC Coaxial HPGe detector system "ORTEC Coax"

ORTEC Model SGD-GEM-25175, SN: 38-P21321B, $55.7 \mathrm{~mm}$ dia by $56.2 \mathrm{~mm}$ thick

LANL Data Acquisition System with ORTEC Coaxial Detector

ORTEC DSPEC Digital Gamma-Ray Spectrometer System

IBM 600E Think Pad Computer

\section{LANL Canberra Coaxial HPGe detector system "Canberra Coax"}

Canberra Model GC2518, SN: 9953619, $60 \mathrm{~mm}$ dia by $42 \mathrm{~mm}$ thick

LANL Data Acquisition Ssystem with Canberra Coax

ORTEC DSPEC Plus Digital Gamma-Ray Spectrometer System

IBM 600E Think Pad Computer

\section{GREEN STAR DATA ACQUISITION SYSTEM SETUP}

The SBS emulator program needs to know the port address and interrupt vectors to be used for the installed SBS-60 board. These parameters are determined and identified during the board installation. On-board port address adjustments may be made by changing the jumper positions on the SBS-60. The high voltage (HV) range and polarity are set by proper positioning of the corresponding HV modules on the SBS-60 board.

The menu in the SBS emulator program is used to set the required detector voltage and the HV rise-time rate. When fixing the high voltage, one has to wait a few moments for the system to reach equilibrium. The emulator program is also used to adjust the system gain, pulse-shaping time constants, baseline restorer rate settings, and the pole-zero (PZ) adjustment. The PZ adjustment may be done automatically or manually for best results.

\footnotetext{
** NIM - Nuclear Instrumentation Module.
} 
The SBS-60 uses the time-variant pulse shaping method. The spectrometer busy time is determined by the corresponding weighting function. To shorten it (important for high count-rate applications to reduce the pulse pile-up), Green Star brought two pilot models of a new special pulse-shaper board. The pulse-shaping adjustments controls were on the pilot boards (used with the two coaxial detector systems) and required manual adjustments with each change of shaping parameters. In the future these adjustments will be made through the SBS emulator program.

\section{Green Star Data Acquisition System Specifications}

\section{The SBS-60 main parameters}

\begin{tabular}{|c|c|}
\hline Parameter & Value, comments \\
\hline Type of interface with PC & ISA \\
\hline Number of channels & $16 \mathrm{k}, 8 \mathrm{k}, 4 \mathrm{k}, 2 \mathrm{k}, 1 \mathrm{k}, 0.5 \mathrm{k}$ \\
\hline $\mathrm{ADC}$ & $3.8 \mu$ s fixed time \\
\hline LLD & $0-100 \%, 1$ part in $8 \mathrm{k}$ \\
\hline Zero & Programmable with 1 channel resolution \\
\hline INL & For amp+ADC $<0.025$ on $98 \%$ \\
\hline DNL & $<0.25 \%$ on $98 \%$ \\
\hline Pulse pair resolution of pile-up rejector & $600 \mathrm{~ns}$ \\
\hline Gain range & 5 to 1280 , resolution $1 / 8000$ \\
\hline Shaping time & $1,2,4,8 \mu \mathrm{s}$ \\
\hline $\mathrm{P} / \mathrm{Z}$ & Automatic software or manual set, $\geq 40 \mu \mathrm{s}$ \\
\hline Gain drift & $\begin{array}{l}\text { Whole amp. + ADC }<0.005 \% \text {, } \\
\text { zero }<0.0025 \% / \mathrm{C}\end{array}$ \\
\hline Overload recovery & 2.5 pulse widths \\
\hline Noise & $2 \mu \mathrm{V}$ at gain 1000 \\
\hline Restorer & Active gated \\
\hline Spectrum broadening & $\begin{array}{l}<15 \% / 50 \mathrm{k} \text { pps , tested with ORTEC } 25185 \text {, resistor } \\
\text { feedback, typical from } 1.75 \text { to } 2.0 \mathrm{keV} \text { on Co- } 60\end{array}$ \\
\hline Count-rate stability & $<0.025 \% / 50 \mathrm{k}$ pps, $4 \mu \mathrm{s}$ shaping time, TRP preamp \\
\hline HV ranges & $\begin{array}{l}20-5000 \mathrm{~V} @ 100 \mu \mathrm{A} \\
5-1250 \mathrm{~V} @ \% 00 \mu \mathrm{A} \\
\end{array}$ \\
\hline Ripple and noise & $<3 \mathrm{mV}$ \\
\hline Temp. coefficient & $<50 \mathrm{ppm} / \mathrm{C}$ \\
\hline Regulation & $\begin{array}{l}\mathrm{R}_{\text {out }}=6.6 \mathrm{MOhm} / 5 \mathrm{kV} \\
\mathrm{R}_{\text {out }}=30 \mathrm{kOhm} / 1.2 \mathrm{kV} \\
\text { determined by filter, HV feedback loop is before filter } \\
\mathrm{HV} \text { adjustability - } 1 / 4096 \text { part of full range. } \\
\mathrm{HV} \text { rise-time rate is adjustable from } 10 \text { to } 9999 \text { seconds. }\end{array}$ \\
\hline Overload protection & With filters may withstand short circuiting. \\
\hline $\mathrm{PC}$ read/verify of HV range, detector voltage and polarity & Yes \\
\hline Memory & On board FIFO \\
\hline Parameter controls and settings & $100 \%$ computer control except HV range and polarity \\
\hline Power consumption & $2 \mathrm{~W}$ \\
\hline Possibility to support multiple SBS boards in a single PC & Yes \\
\hline Firmware number readability by PC & Yes \\
\hline Stabilization & By program \\
\hline Dimensions & Standard ISA half-size board (length $137 \mathrm{~mm}$ ) \\
\hline Weight & About $200 \mathrm{~g}$ \\
\hline
\end{tabular}


We tested three Green Star SBS-60 spectrometers. One was a single board SBS-60 spectrometer. The other two Green Star systems included a second, experimental pulse-shaping board. The Green Star boards are shown on top of the ORTEC DSPEC Plus system in Fig. 1 with the experimental dual board version on the right and the single board version on the left.

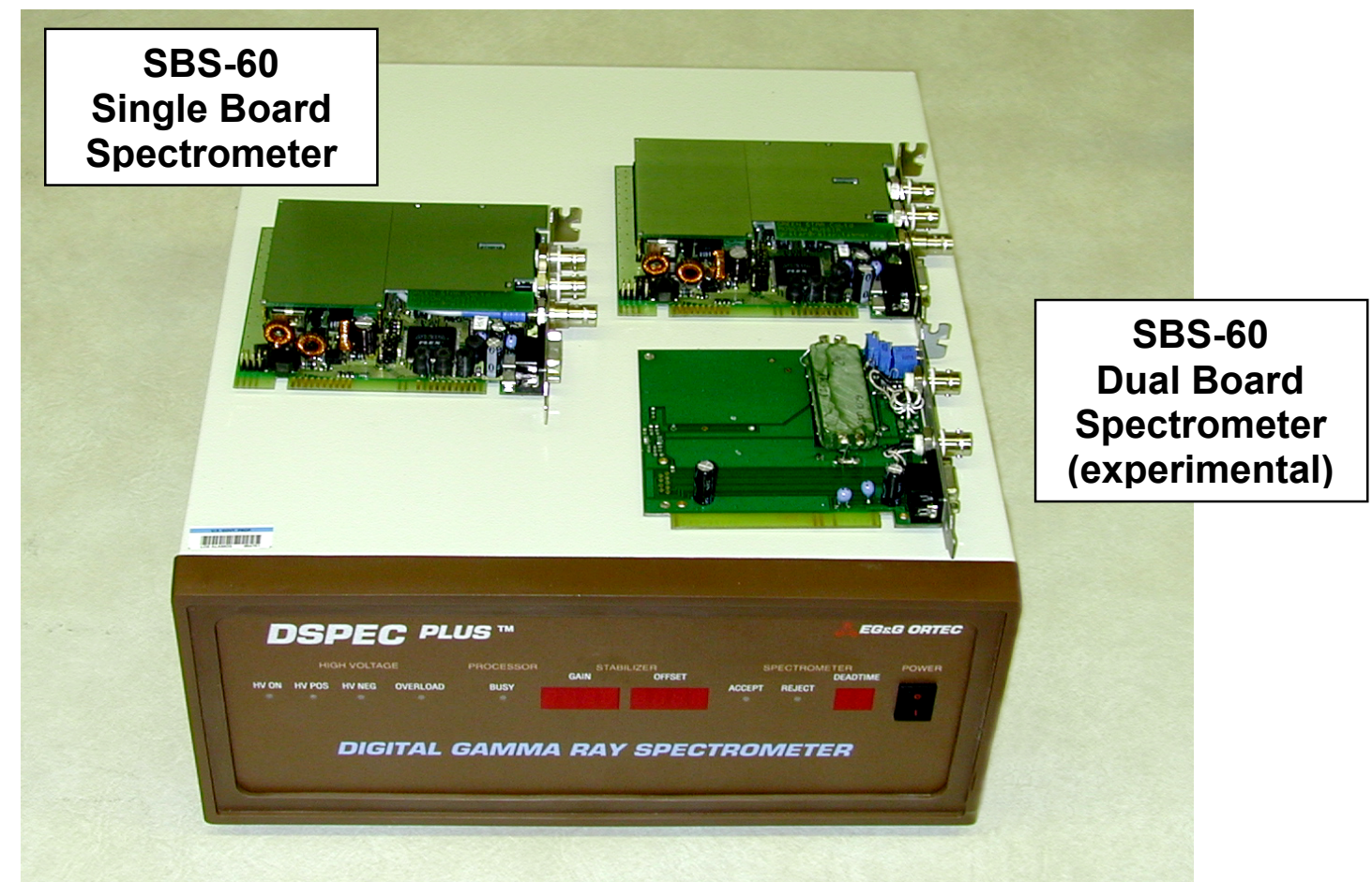

Fig. 1. The single board and dual board SBS-60 systems shown with the ORTEC DSPEC Plus electronics.

The Green Star spectrometers were set up with the LANL detectors and Green Star and LANL computer systems (Table I) below. The Green Star boards only operate with Windows 95 and 98 and do not operate under Windows NT.

TABLE I. Configuration of Green Star Spectrometers/Detector/Computer Systems.

\begin{tabular}{|l|l|l|l|}
\hline \multicolumn{1}{|c|}{ Detector } & \multicolumn{1}{|c|}{ Green Star Board Type } & \multicolumn{1}{c|}{ Computer } & \multicolumn{1}{c|}{ Operating System } \\
\hline \hline Planar & Single board SBS-60 & MD\&I Ace High Notebook & Windows 95 \\
ORTEC Coax & Dual board SBS-60 & Gateway P5/200 & Windows 95 \\
Canberra Coax & Dual board SBS-60 & Gateway P6/400 & Windows 98 \\
\hline
\end{tabular}

The detectors and electronics were configured as they were for the 1997 testing. The detectors and preamps received their high voltage and preamp power from the Green Star SBS-60. The two independent outputs from the preamplifier were fed to the inputs of the SBS-60 and the LANL electronics as shown in Fig. 2. 




Fig. 2. Basic electronics interconnections for LANL/Green Star SBS-60 spectrometer tests.

\section{DATA ACQUISITION AND ANALYSIS}

We acquired data on the planar detector using $1 \mu$ s triangular shaping on the LANL ORTEC 672 amplifier. The Green Star spectrometer was also set at $1 \mu$ s shaping. The LANL digital spectrometer data from both coaxial detectors was acquired with a $2 \mu$ s (analog shaping equivalent) time constant using a rise time setting of $4 \mu$ s. The Green Star spectrometers operating with the coaxial detectors collected data with a $2 \mu$ s shaping time. We also made a limited number of measurements using a $1 \mu$ s shaping time (Green Star (GS) system) and 1.2 $\mu \mathrm{s} / 2.4 \mu$ s rise time (LANL DSPEC Plus system) with the Canberra coaxial detector.

Amplifier input counting rates were determined from the SBS-60 software, the ORTEC DSPEC Plus software, or the counter/timer in the planar detector NIM bin. Green Star data acquisition was controlled by Green Star's own multichannel analyzer (MCA) emulator software. The FRAM software controlled LANL data acquisition. The Green Star spectral data were converted, offline, to an ASCII format readable by FRAM. The FRAM and converted Green Star spectral data were analyzed offline with version 3.2 of FRAM on a PIII/500 MHz system running Windows NT. The plutonium isotopic analysis was carried out using the Coax8k125.3 FRAM parameter file analyzing data in the $120-450 \mathrm{keV}$ region. The same spectral data were also analyzed using the ShieldCoax4.3 FRAM parameter file analyzing data in the $200-800 \mathrm{keV}$ region to simulate a shielded sample.

The analysis of the throughput and resolution data was carried out offline using region of interest (ROI) methods with the ORTEC Maestro Multichannel Analyzer emulation software. 


\section{RESOLUTION AND THROUGHPUT MEASUREMENTS}

Resolution, throughput, and relative peak position of the $122 \mathrm{keV}{ }^{57} \mathrm{Co}$ peak and $1332 \mathrm{keV}{ }^{60} \mathrm{Co}$ peak were measured at input counting rates of $3,10,20,40,60,80$, and $100 \mathrm{kHz}$. The $122 \mathrm{keV}$ ${ }^{57} \mathrm{Co}$ peak was nominally placed in ch 3200 of a $4096 \mathrm{ch}$ spectrum. The $1332 \mathrm{keV}{ }^{60} \mathrm{Co}$ peak was nominally placed in ch 7800 of an 8192 ch spectrum. Results are displayed in Figs. 3-5.

\section{ORTEC Planar Detector, 1 s Shaping Time}
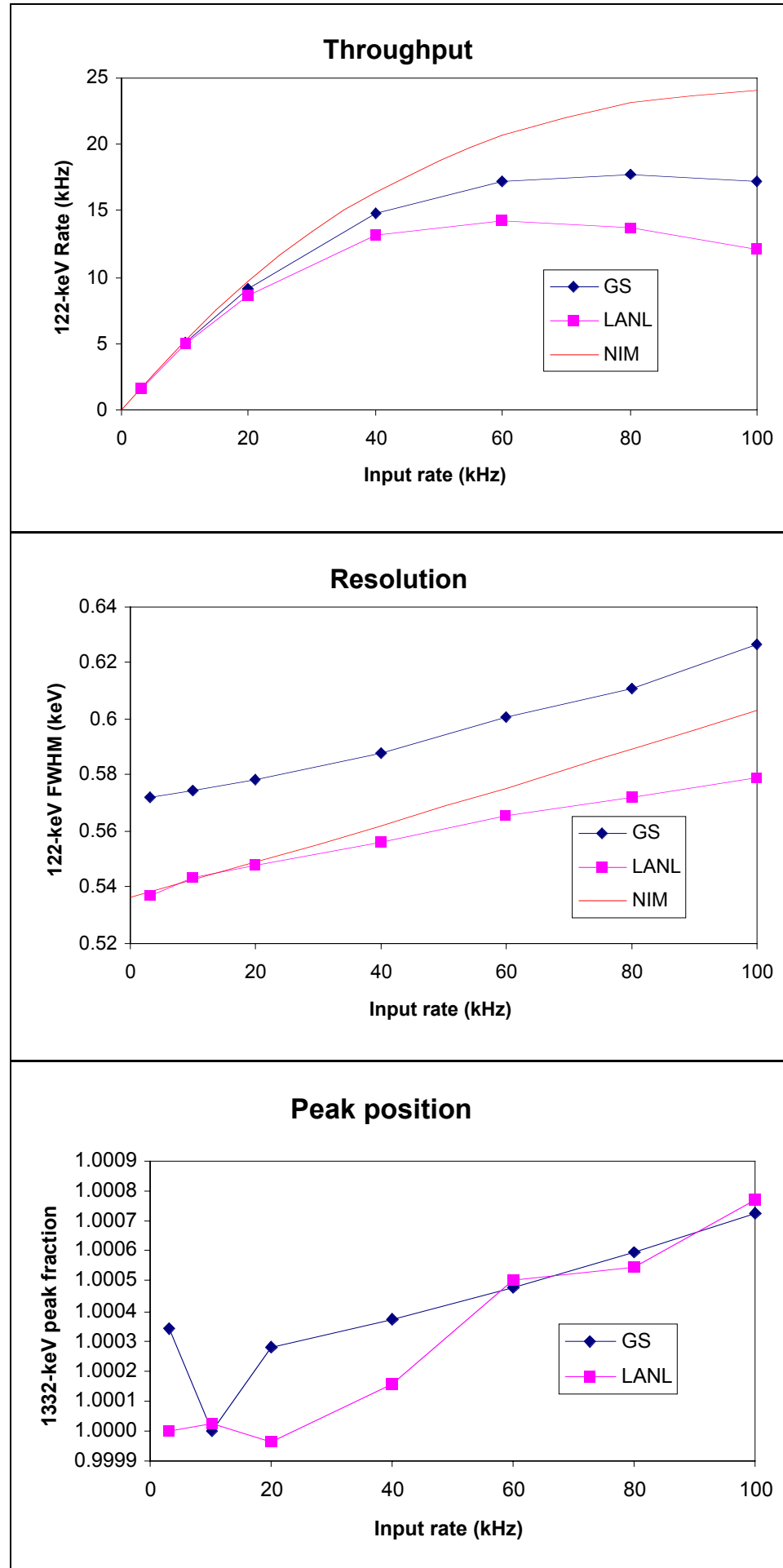

Fig. 3. Comparative resolution and throughput as a function of input count rate using the ORTEC planar detector, NIM electronics with a $1 \mu$ s shaping time for LANL measurements, SBS-60 single board for Green Star measurements, and $a^{57}$ Co source. The smooth lines (no data points) denoted "NIM" represent the data from the NIM system with the same planar detector taken a few weeks earlier. Note the throughput of LANL's NIM system in this evaluation appears much lower than that taken a few weeks earlier. In this evaluation the pile-up rejector (PUR) from the amplifier was connected to the PUR input of the MatchMaker instead of the ADC. The timing mismatch between the PUR and the ADC output caused the reduced throughput of the NIM in this evaluation. The earlier data is shown to illustrate the true capabilities of the NIM system. 


\section{Canberra Coaxial Detector, $2 \mu$ s Shaping Time}
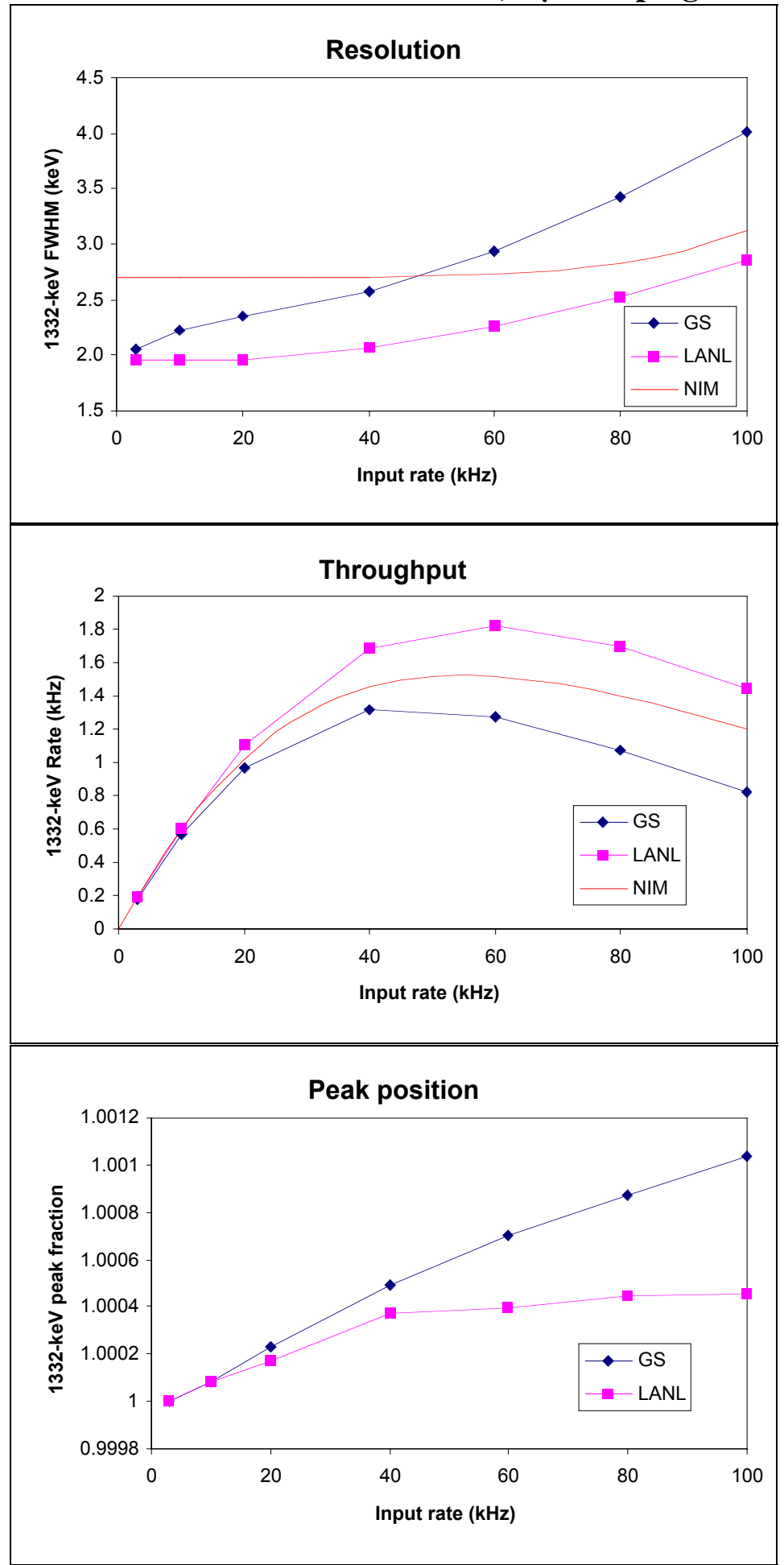

Fig. 4. Comparative resolution and throughput and peak position as a function of input count rate using the Canberra coaxial detector and ${ }^{60} \mathrm{Co}$ source. The Green Star system was the two board MCA and the LANL system was the DSPEC Plus. The shaping time of the system was $2 \mu$ s. The smooth lines denoted "NIM" represent the data of the NIM system (same NIM system used with the planar detector) with the same coaxial detector taken a few weeks earlier. 


\section{Canberra Coaxial Detector, $1 \mu$ s Shaping Time}
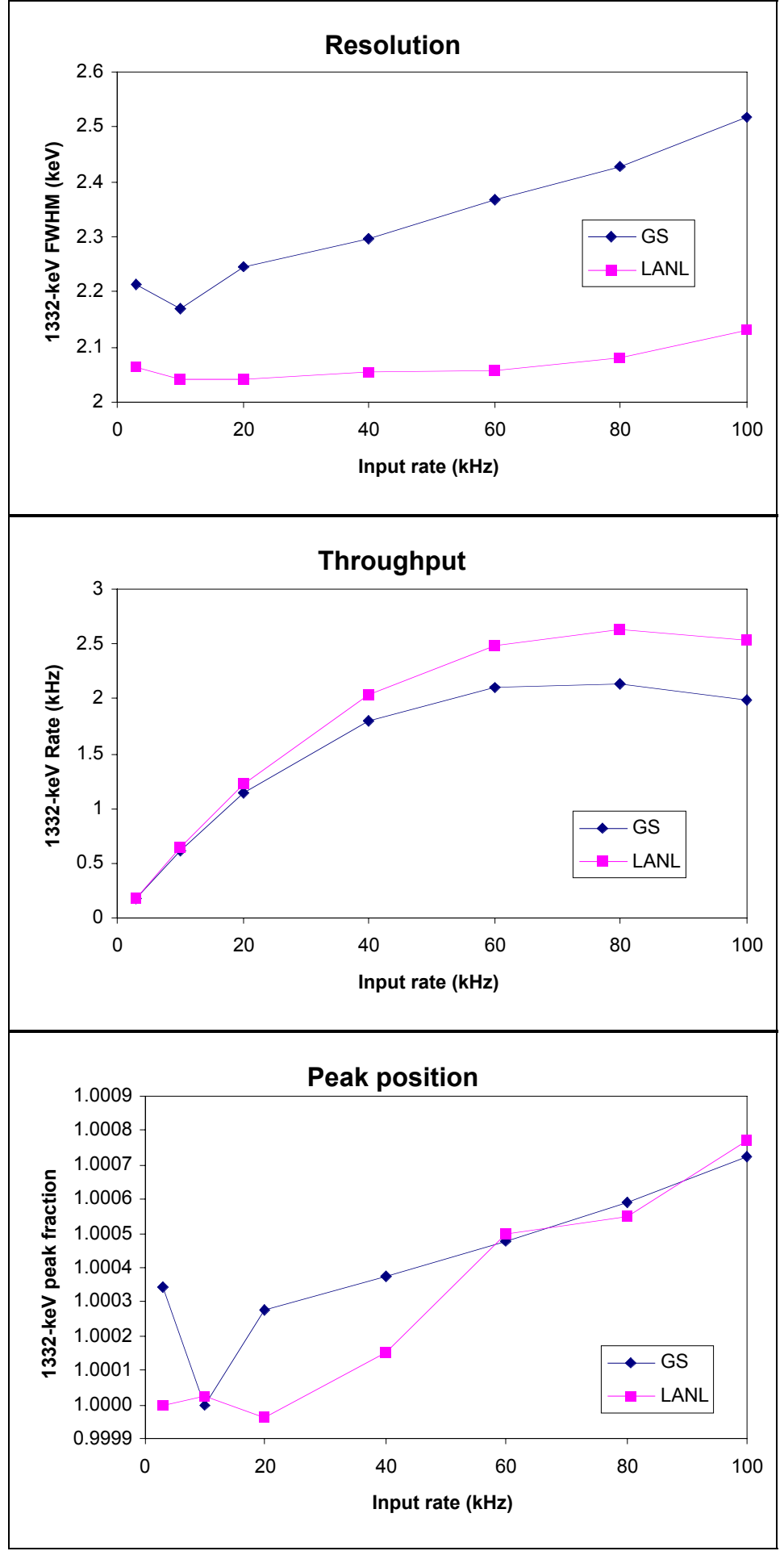

Fig. 5. Comparative resolution and throughput as a function of input count rate using the Canberra coaxial detector and ${ }^{60}$ Co source. The Green Star system was the two board MCA and the LANL system was the DSPEC Plus. The shaping time was $1 \mu$ s for the Green Star system and $1.2 \mu \mathrm{s}$ (2.4 $\mu$ s rise time) for the DSPEC Plus system. 


\section{DISCUSSION OF RESOLUTION, THROUGHPUT AND COUNT RATE STABILITY MEASUREMENTS}

These measurements compare the SBS-60 with state-of-the-art electronics. The comparative sizes of the systems have been shown in Fig. 1. While the commercial US systems did outperform the SBS-60 in most measures, the overall performance of the SBS-60 was very commendable considering its compactness. In two out of three comparisons, the SBS-60 equaled the commercial US systems in the count rate stability of the peak position.

Green Star calculations of the throughput for various SBS-60 shaping times were found to be in agreement with the measured throughputs.

\section{INTEGRAL NONLINEARITY TESTS}

We tested the systems for integral linearity using an ORTEC Model 448 Research Pulser and used the full $16 \mathrm{~K}$ range of the systems' ADCs.

The integral nonlinearity was better for the US commercial digital spectrometer systems compared to the dual board Green Star SBS-60 system (Figs. 6 and 7). The integral nonlinearity for the single board Green Star SBS-60 system and the US analog NIM system was equal (Fig. 8).

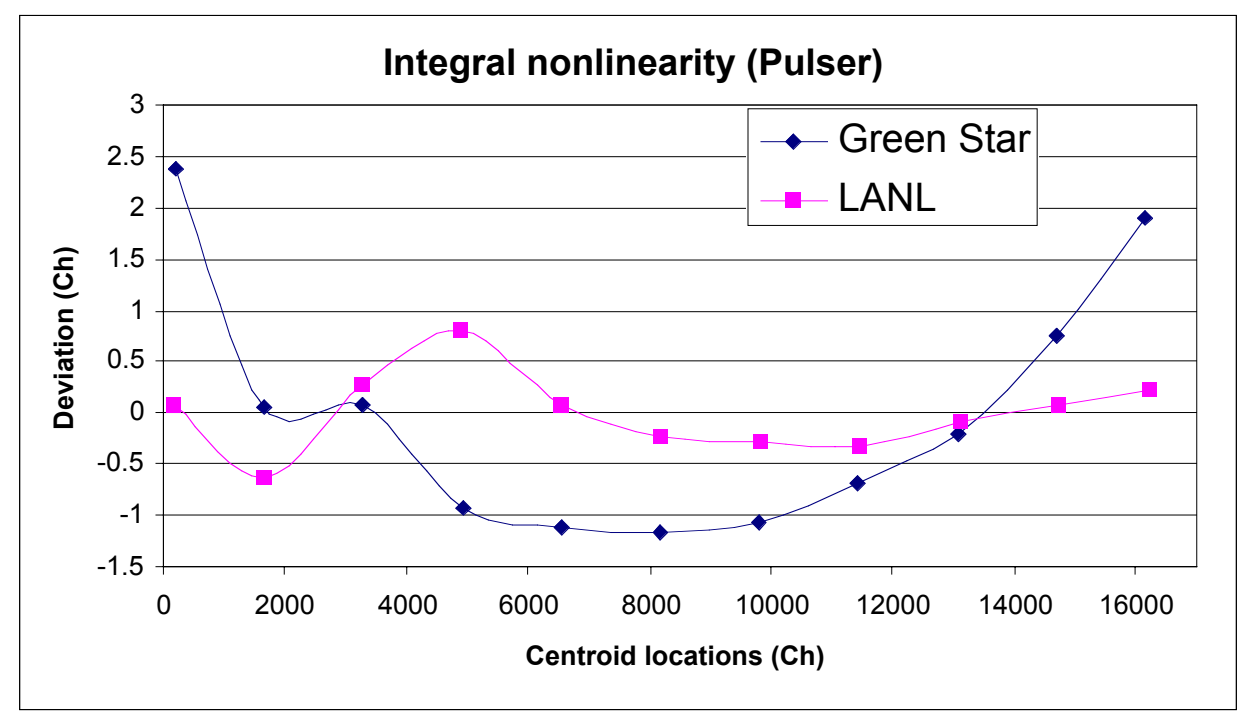

Fig. 6. Results of the integral nonlinearity tests for the ORTEC coaxial detector. The Green Star system is a dual board spectrometer and the LANL system is the DSPEC. 


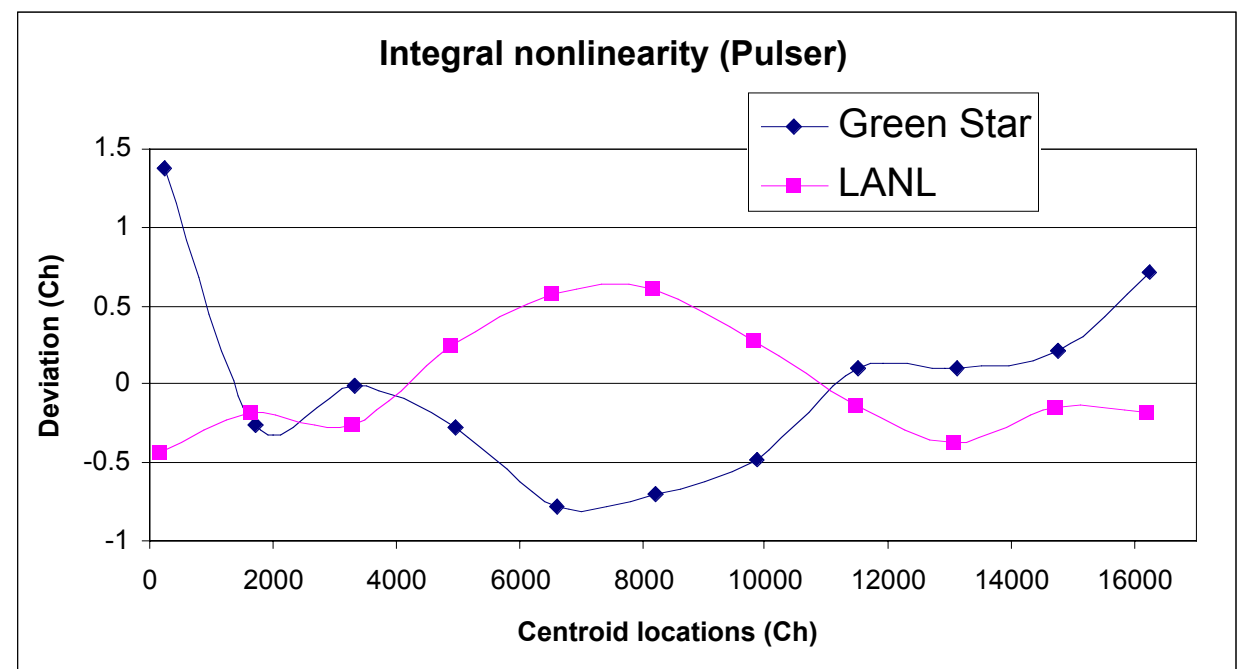

Fig. 7. Results of the integral nonlinearity tests for the Canberra coaxial detector. The Green Star system is a dual board spectrometer and the LANL system is the DSPEC Plus.



Fig. 8. Results of the integral nonlinearity tests for the Canberra planar detector. The Green Star system is a single board spectrometer and the LANL system is the NIM system.

\section{PEAK POSITION DRIFT}

We measured the peak position of the $122 \mathrm{keV}{ }^{57} \mathrm{Co}$ peak every 15 minutes by using the planar detector with the NIM system (LANL) and the single board spectrometer (Green Star). These measurements were carried out for 16 hours at a counting rate of $20 \mathrm{kHz}$ and are shown in Fig. 9. The Green Star system drifted about $0.05 \%$ peak-to-peak while the NIM system drifted $0.03 \%$. 


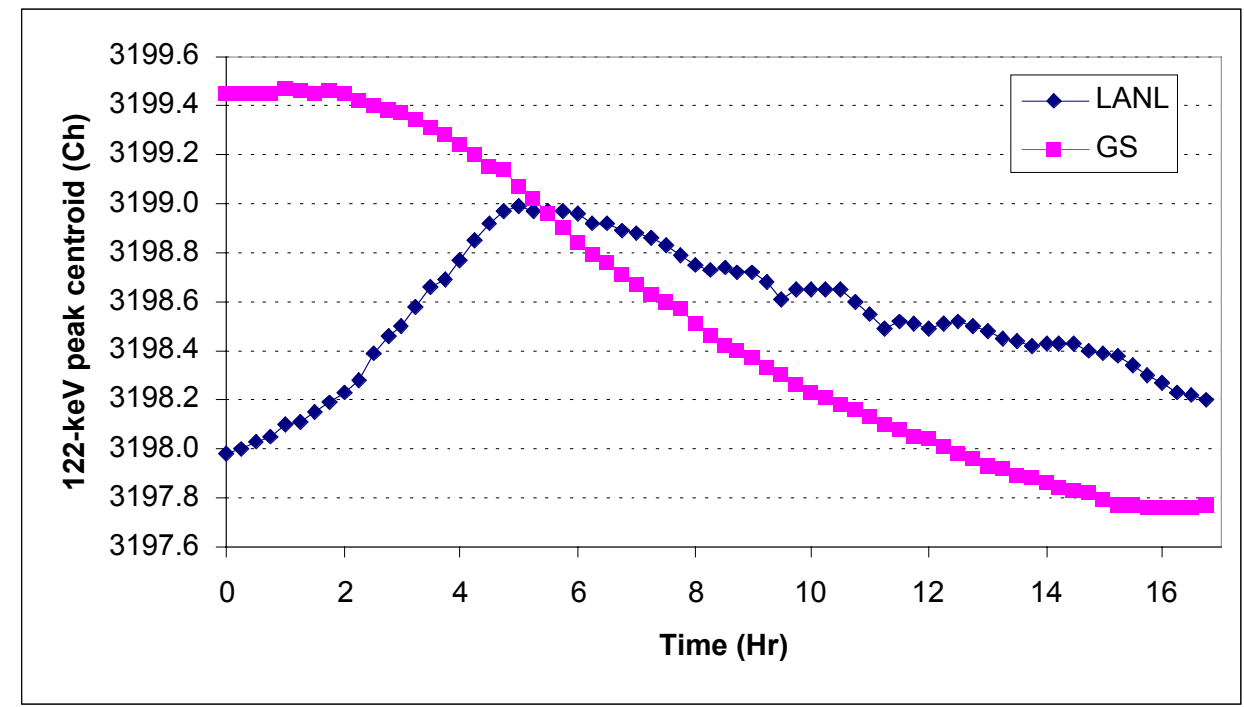

Fig. 9. Peak position stability of the NIM system (LANL) and the SBS-60 single board spectrometer (GS) for a ${ }^{57}$ Co source using 15 min measurements at a count rate of $20 \mathrm{kHz}$.

\section{PLUTONIUM ISOTOPIC ANALYSIS RESULTS}

We made multiple measurements using all three detector systems of gamma-ray spectra from plutonium samples with well-known isotopic composition. We deliberately chose samples with low burnup plutonium because the end product of this work is to be a system to measure isotopic composition of plutonium from dismantled nuclear weapons. The isotopic composition of the three samples used is shown in Table II. The spectral data from the two MCA systems used with each detector were analyzed with version 3.2 of the Los Alamos PC/FRAM code.

TABLE II. Isotopic Characteristics of Samples on October 13, 1999.

\begin{tabular}{|c|l|c|c|c|c|c|c|l|}
\hline $\begin{array}{c}\text { Sample } \\
\text { ID }\end{array}$ & $\begin{array}{c}\text { Grams } \\
\mathrm{Pu}\end{array}$ & $\begin{array}{c}\mathrm{Wt} \% \\
\mathrm{Pu} 238\end{array}$ & $\begin{array}{c}\mathrm{Wt} \% \\
\mathrm{Pu} 239\end{array}$ & $\begin{array}{c}\mathrm{Wt} \% \\
\mathrm{Pu} 240\end{array}$ & $\begin{array}{c}\mathrm{Wt} \% \\
\mathrm{Pu} 241\end{array}$ & $\begin{array}{c}\mathrm{Wt} \% \\
\mathrm{Pu} 242\end{array}$ & $\begin{array}{c}\mathrm{Ppm} \\
\mathrm{Am} / \mathrm{Pu}\end{array}$ & $\mathrm{mW} / \mathrm{gPu}$ \\
\hline \hline STDISO3 & 10.97 & 0.0058 & 96.357 & 3.561 & 0.0585 & 0.0183 & 688.6 & 2.2244 \\
STDISO6 & 8.45 & 0.0127 & 93.641 & 6.131 & 0.1582 & 0.0570 & 1626.2 & 2.5037 \\
STDISO9 & 11.88 & 0.0192 & 92.795 & 6.895 & 0.2171 & 0.0734 & 2127.5 & 2.6375 \\
\hline
\end{tabular}

We made repeated 1-h measurements at a counting rate of $30 \mathrm{kHz}$ using a $1 \mu$ s shaping time on the planar detector and a $2 \mu$ s shaping time on the coaxial detectors. Some measurements were made with the Canberra coaxial detector with a shaping time of $1 \mu$ s and some were made with 15 -min count times. These deviations from the standard measurement conditions are noted in the tables.

The analysis results are displayed in the following tables. The results are expressed as a ratio of the average measured value to the accepted value from Table II. The percent relative standard deviation (\%RSD) numbers are the percent relative standard deviation from the distribution of the indicated number of measurements. The operator entered ${ }^{242} \mathrm{Pu}$ from the values in Table II.

In Table III we display the \%RSD predicted in the FRAM software from propagated counting statistics for the important ${ }^{240} \mathrm{Pu}$ isotope. This gives a better comparison of the counting statistics 
errors between the systems than does the comparison from repeated measurements because of the relatively small number of repeated measurements.

TABLE III. FRAM Predicted \%RSD for ${ }^{240} \mathrm{Pu}$ from Counting Statistics.

\begin{tabular}{|l|c|c|c|}
\hline \multicolumn{1}{|c|}{ Detector } & Standard & Green Star \%RSD & LANL \%RSD \\
\hline \hline & & & \\
\hline Planar & STDISO3 & 1.51 & 1.51 \\
\hline Planar & STDISO6 & 1.29 & 1.26 \\
\hline Planar (15 min) & STDISO9 & 2.90 & 2.54 \\
\hline & & & $0.77(1.5 \mathrm{hr})$ \\
\hline Canberra Coax & STDISO6 & $1.25(1 \mathrm{hr})$ & 3.45 \\
\hline Canberra Coax $(15 \mathrm{~min})$ & STDISO3 & 3.60 & 0.97 \\
\hline Canberra Coax & STDISO6 & 1.01 & 0.98 \\
\hline Canberra Coax & STDISO9 & 1.22 & 1.13 \\
\hline & & & 1.96 \\
\hline ORTEC Coax & STDISO9 & 1.26 & 2.16 \\
\hline ORTEC Coax & STDISO3 & 2.13 & \\
\hline ORTEC Coax $(15 \mathrm{~min})$ & STDISO6 & 2.48 & \\
\hline
\end{tabular}

The differences seen here mainly reflect the throughput differences among the systems as illustrated in Figs. 3-5.

The first group of results in Tables IV-VI from the three detectors is from analysis in the 120-450 keV region. These data were analyzed using the FRAM parameter file Coax8k125.3 for the measurements from the coaxial detectors and the parameter file Widerange6.105 for the planar detector measurements. There appears to be no difference between the Green Star SBS60 results and the results from the commercial US systems. The \%RSD values bounce around because they are computed from the distribution of the repeated measurements and themselves have a relative error of $[1 / \operatorname{sqrt}(2 *(n-1))]$.

Tables VII-IX display the same results ordered by detector and measurement system with the results over all measurements averaged for each detector/measurement system combination. Again, viewed in this manner, there appears to be no significant difference among the measurements systems. 







\begin{tabular}{|c|c|c|}
\hline 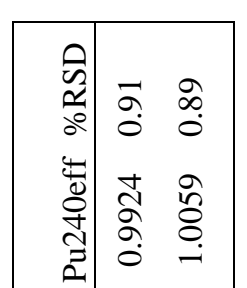 & 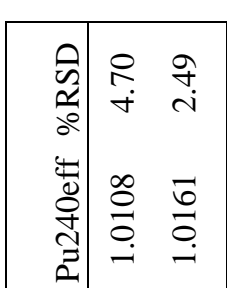 &  \\
\hline 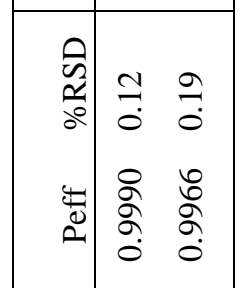 & 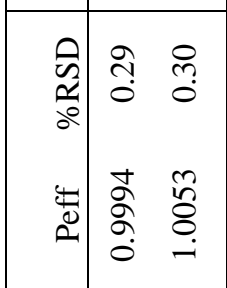 & 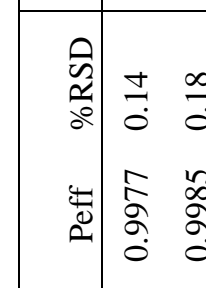 \\
\hline 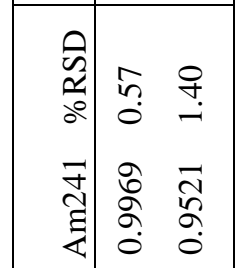 & 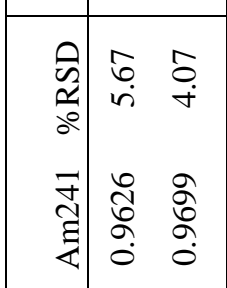 & 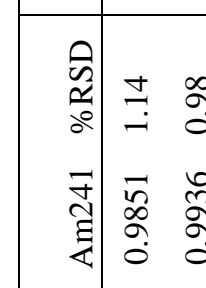 \\
\hline  & 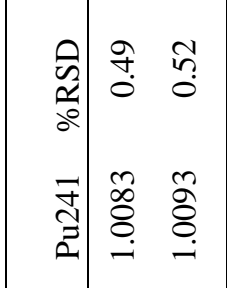 &  \\
\hline 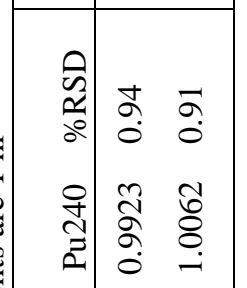 & 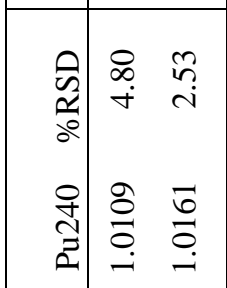 & 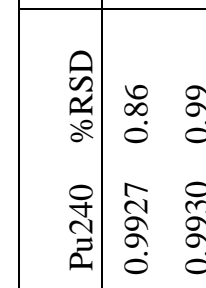 \\
\hline 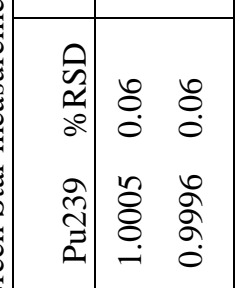 & 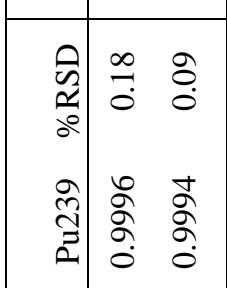 & \\
\hline 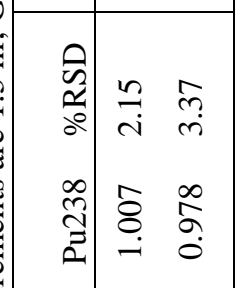 & 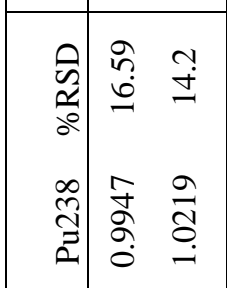 & \\
\hline  & 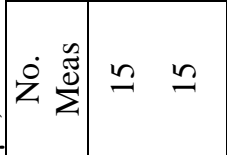 & 淁里 \\
\hline
\end{tabular}




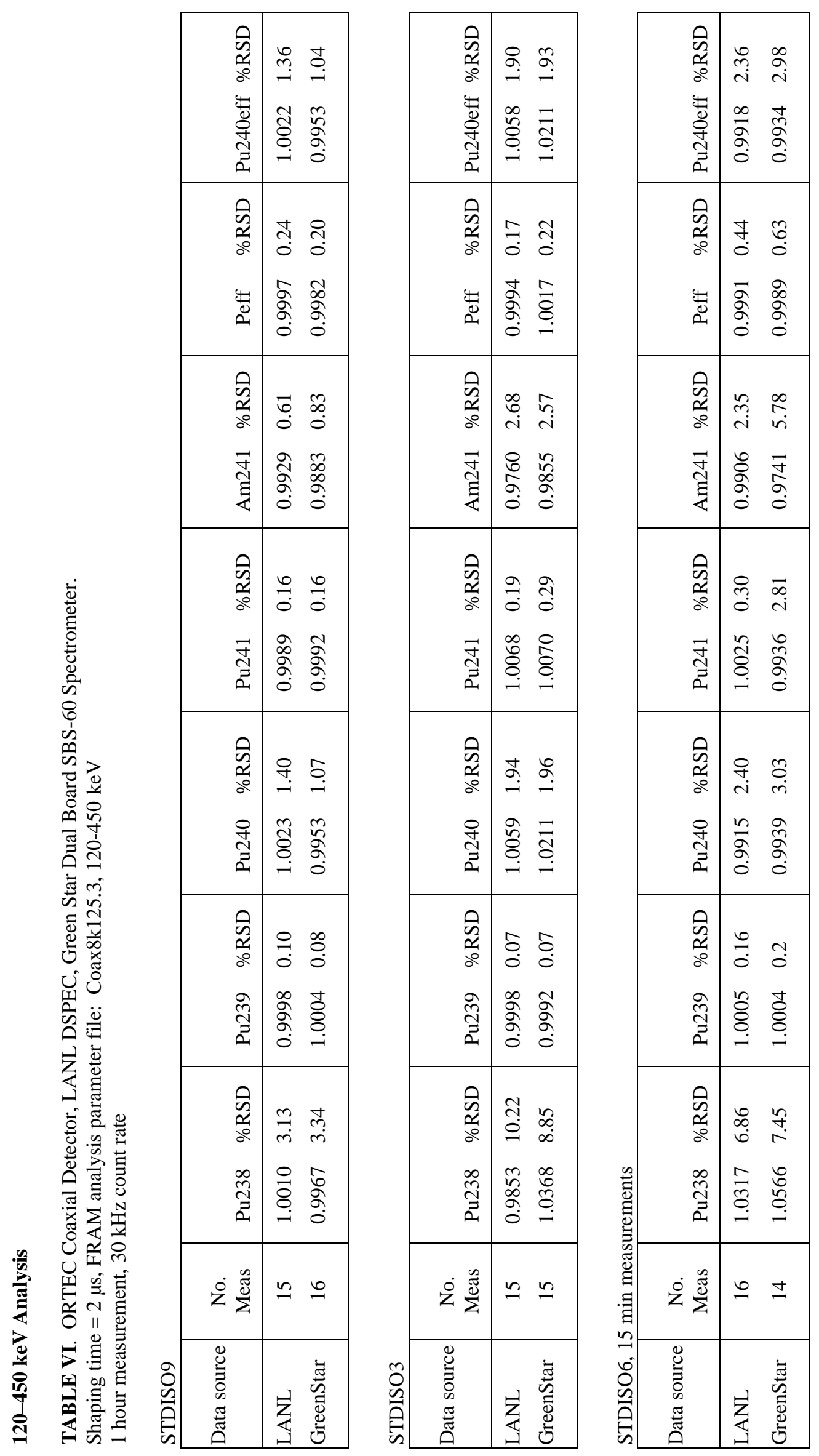




\section{0-450 keV Analysis}

TABLE VIIa

Average: Measured/Certified

Green Star SBS-60 Single Board Spectrometer

Planar Detector, 120-450 keV Analysis

\begin{tabular}{|l|llllllc|}
\hline Sample & Pu238 & Pu239 & Pu240 & Pu241 & Am241 & Peff & Pu240eff \\
\hline STDISO3 & 1.0608 & 1.0003 & 0.9921 & 1.0076 & 0.9754 & 0.9993 & 0.9926 \\
STDISO6 & 1.0335 & 0.9996 & 1.0054 & 0.9993 & 0.9931 & 1.0011 & 1.0054 \\
STDISO9 & 1.0116 & 0.9999 & 1.0018 & 0.9963 & 0.9965 & 1.0004 & 1.0018 \\
\hline Average & 1.0353 & 0.9999 & 0.9998 & 1.0011 & 0.9883 & 1.0003 & 0.9999 \\
\hline
\end{tabular}

TABLE VIIb

Average: Measured/Certified

LANL NIM System

Planar Detector, 120-450 keV Analysis

\begin{tabular}{|l|llllllc|}
\hline Sample & Pu238 & Pu239 & Pu240 & Pu241 & Am241 & Peff & Pu240eff \\
\hline STDISO3 & 1.0181 & 1.0007 & 0.9800 & 1.0052 & 0.9953 & 0.9984 & 0.9804 \\
STDISO6 & 1.0187 & 0.9997 & 1.0039 & 0.9991 & 0.9944 & 1.0006 & 1.0039 \\
STDISO9 & 1.0149 & 1.0002 & 0.9967 & 0.9964 & 1.0004 & 1.0002 & 0.9968 \\
\hline Average & 1.0172 & 1.0002 & 0.9935 & 1.0002 & 0.9967 & 0.9997 & 0.9937 \\
\hline
\end{tabular}

\section{TABLE VIIIa}

Average: Measured/Certified

Green Star SBS-60 Dual Board Spectrometer

Canberra Coaxial Detector, 120-450 keV Analysis

\begin{tabular}{|l|ccccccc|}
\hline Sample & Pu238 & Pu239 & Pu240 & Pu241 & Am241 & Peff & Pu240eff \\
\hline STDISO6 & 0.978 & 0.9996 & 1.0062 & 1.0083 & 0.9521 & 0.9966 & 1.0059 \\
STDISO3 & 1.0219 & 0.9994 & 1.0161 & 1.0093 & 0.9699 & 1.0053 & 1.0161 \\
STDISO6 & 0.9977 & 1.0004 & 0.993 & 1.0036 & 0.9936 & 0.9985 & 0.9931 \\
STDISO9 & 0.9994 & 1.0005 & 0.9928 & 1.0042 & 0.9566 & 0.9950 & 0.9929 \\
\hline Average & 1.0063 & 1.0001 & 1.0006 & 1.0057 & 0.9734 & 0.9996 & 1.0007 \\
\hline
\end{tabular}

\section{TABLE VIIIb}

Average: Measured/Certified

LANL DSPEC Plus

Canberra Coaxial Detector, 120-450 keV Analysis

\begin{tabular}{|l|ccccccc|}
\hline Sample & Pu238 & Pu239 & Pu240 & Pu241 & Am241 & Peff & Pu240eff \\
\hline STDISO6 & 1.007 & 1.0005 & 0.9923 & 1.0039 & 0.9969 & 0.9990 & 0.9924 \\
STDISO3 & 0.9947 & 0.9996 & 1.0109 & 1.0083 & 0.9626 & 0.9994 & 1.0108 \\
STDISO6 & 0.9931 & 1.0005 & 0.9927 & 1.0047 & 0.9851 & 0.9977 & 0.9927 \\
STDISO9 & 0.9990 & 0.9997 & 1.0033 & 1.0008 & 0.9869 & 0.9992 & 1.0032 \\
\hline Average & 0.9956 & 0.9999 & 1.0023 & 1.0046 & 0.9782 & 0.9988 & 1.0022 \\
\hline
\end{tabular}


TABLE IXa

Average: Measured/Certified

Green Star SBS-60 Dual Board Spectrometer

ORTEC Coaxial Detector, 120-450 keV Analysis

\begin{tabular}{|l|ccccccc|}
\hline Sample & Pu238 & Pu239 & Pu240 & Pu241 & Am241 & Peff & Pu240eff \\
\hline STDISO9 & 0.9967 & 1.0004 & 0.9953 & 0.9993 & 0.9883 & 0.9982 & 0.9953 \\
STDISO3 & 1.0368 & 0.9992 & 1.0211 & 1.0070 & 0.9855 & 1.0017 & 1.0211 \\
STDISO6 & 1.0566 & 1.0004 & 0.9939 & 0.9936 & 0.9741 & 0.9989 & 0.9934 \\
\hline Average & 1.0467 & 0.9998 & 1.0075 & 1.0003 & 0.9798 & 1.0003 & 1.0073 \\
\hline
\end{tabular}

TABLE IXb

Average: Measured/Certified

LANL DSPEC

ORTEC Coaxial Detector, 120-450 keV Analysis

\begin{tabular}{|l|ccccccc|}
\hline Sample & Pu238 & Pu239 & Pu240 & Pu241 & Am241 & Peff & Pu240eff \\
\hline STDISO9 & 1.0010 & 0.9998 & 1.0023 & 0.9989 & 0.9929 & 0.9997 & 1.0022 \\
STDISO3 & 0.9853 & 0.9998 & 1.0059 & 1.0068 & 0.976 & 0.9994 & 1.0058 \\
STDISO6 & 1.0317 & 1.0005 & 0.9915 & 1.0025 & 0.9906 & 0.9991 & 0.9918 \\
\hline Average & 1.0085 & 1.0002 & 0.9987 & 1.0047 & 0.9833 & 0.9993 & 0.9988 \\
\hline
\end{tabular}

\section{HIGH ENERGY REGION “SHIELDED” ANALYSIS, 200-800 keV}

We also analyzed the same data from the two coaxial detectors using the parameter file Shieldcoax4.3 that carries out the analysis in the $200-800 \mathrm{keV}$ region. This analysis may be the most appropriate for this project because the measurements will likely have to be carried out through the walls of an AT400R container. The results from these analyses are displayed in Tables $\mathrm{X}-\mathrm{XI}$.

There are several considerations to be noted for analysis in this region of the spectrum. The ${ }^{240} \mathrm{Pu}$ gamma ray at $642.5 \mathrm{keV}$ is the only gamma ray from this isotope available in this region. Likewise, there is only one ${ }^{238} \mathrm{Pu}$ gamma ray available at $766.4 \mathrm{keV}$. There are no direct gamma rays from ${ }^{241} \mathrm{Pu}$; only the gamma rays from its ${ }^{237} \mathrm{U}$ daughter at $208,267,332,336,368$, and $370 \mathrm{keV}$. This means that the ${ }^{241} \mathrm{Pu}{ }^{237} \mathrm{U}$ decay must be in secular equilibrium $(>45$ days since a chemical separation of uranium), which was not expected to be a problem in this project. The branching intensities for the ${ }^{240} \mathrm{Pu}$ and ${ }^{238} \mathrm{Pu}$ gamma rays in the $200-800 \mathrm{keV}$ region are a factor of 30 and 40 times less than those for the gamma rays used by FRAM in the $120-450 \mathrm{keV}$ region. ( $160.3 \mathrm{keV}$ for ${ }^{240} \mathrm{Pu}$ and $152.7 \mathrm{keV}$ for ${ }^{238} \mathrm{Pu}$ ). This makes the statistical precision poorer for these two isotopes for the small samples used in these measurements relative to the measurements in the $120-450 \mathrm{keV}$ region. This will not be a problem for measurements on the $\mathrm{kg}$ quantities of plutonium planned for the AT400R container. Indeed, there is evidence ${ }^{4}$ for large samples that measurements in the $200-800 \mathrm{keV}$ region may be more precise (lower statistical error) than those in the $120-450 \mathrm{keV}$ region. 
Measurement of the ${ }^{238} \mathrm{Pu}$ isotopic fraction in low burnup plutonium is particularly difficult at 766.4 $\mathrm{keV}$. The gamma ray is weak and has strong interferences from ${ }^{241} \mathrm{Am}$ and ${ }^{239} \mathrm{Pu}$ gamma rays. Data from this region from the STDISO6 sample is shown in Fig. 10.

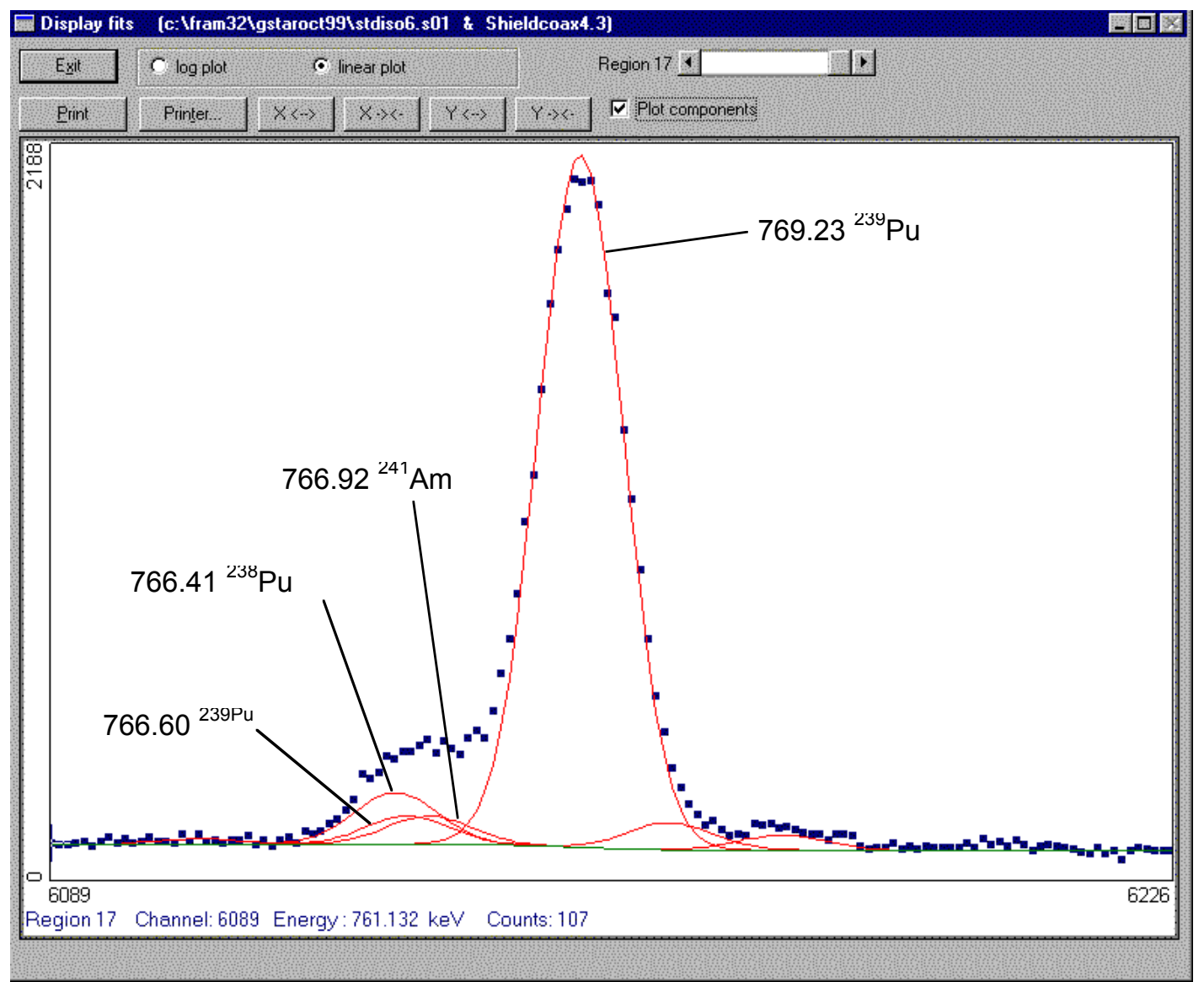

Fig. 10. Spectrum components in the $766 \mathrm{keV}$ region from STDISO6.

The measurements shown in Tables X-XI show general agreement between the analyses of the Green Star data and the US commercial system data for the ${ }^{239} \mathrm{Pu},{ }^{240} \mathrm{Pu},{ }^{241} \mathrm{Pu}$, and ${ }^{241} \mathrm{Am}$ isotopes. However, for the ${ }^{238} \mathrm{Pu}$ isotope, analysis of the Green Star data yields results that are about $15 \%$ higher than the same analysis performed on the data from the US systems. For the two data sets taken with a $1 \mu$ s time constant, the comparison is poorer still. These two data sets (Canberra coax, STDISO3 and Canberra coax, STDISO6) show biases of $230 \%$ and $155 \%$ respectively. The cause is believed to be an imperfect pole/zero adjustment coupled with old components in the pileup rejector of the SBS-60 and is thought to be corrected in later versions with the use of improved components.

We reanalyzed all of the suspect data, both Green Star and LANL, with the tailing on the peaks both fixed and free, figuring that freeing the tails may help the suspected pole/zero problem with the SBS-60. We saw no significant differences between the analyses with the tails fixed and with the tails free. The results from the analyses with the tails free are displayed below. 


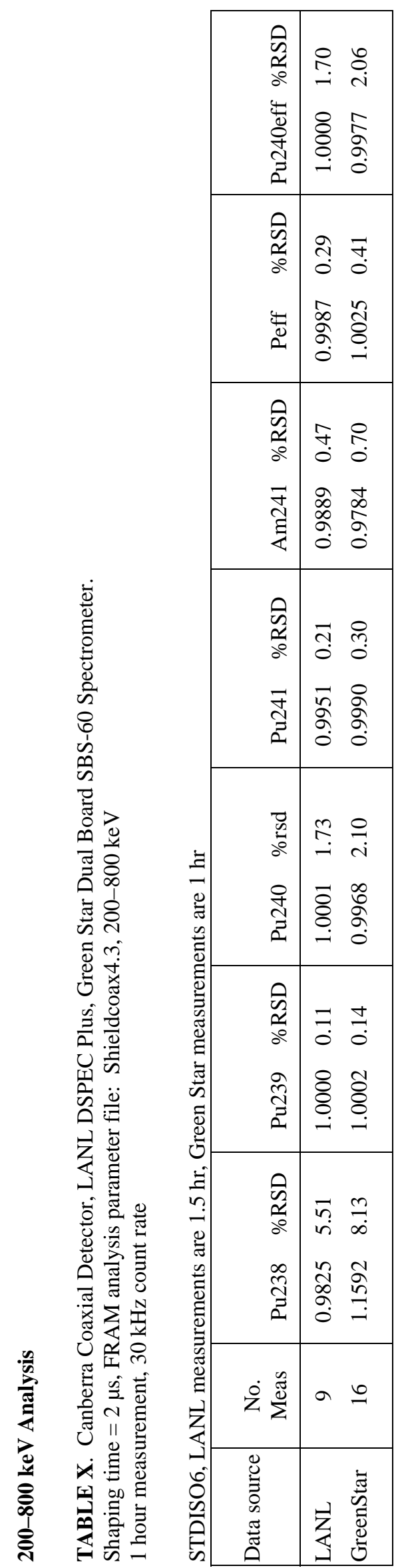

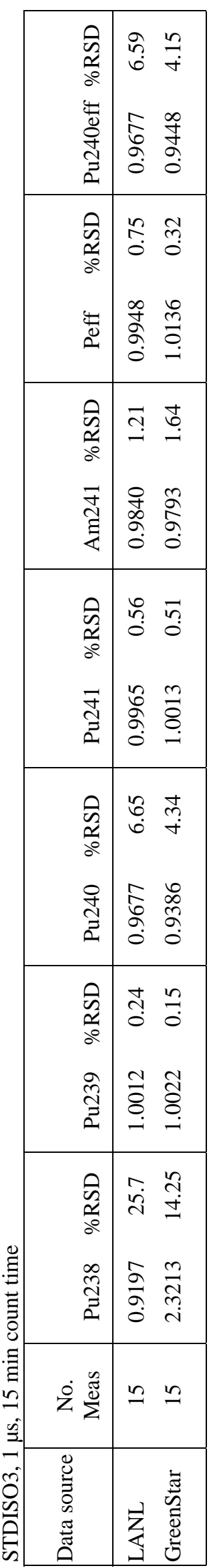

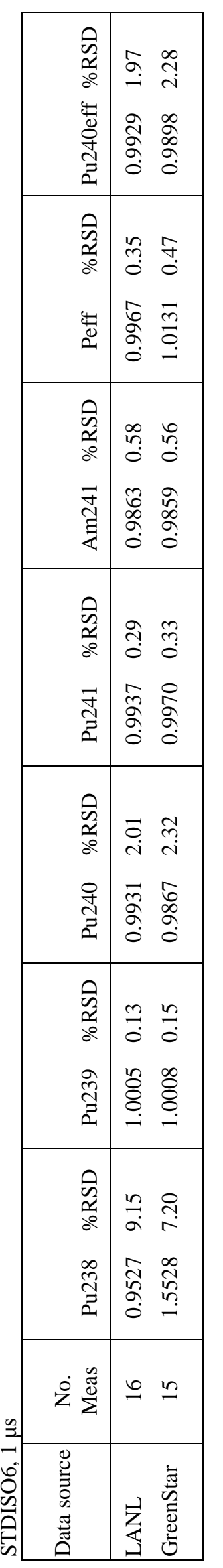

\begin{tabular}{|c|c|}
\hline 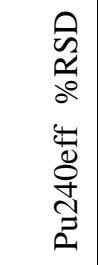 & 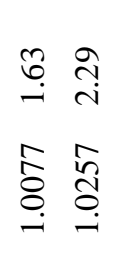 \\
\hline $\begin{array}{l}0 \\
\frac{n}{8} \\
\frac{0}{0}\end{array}$ & $\begin{array}{ll}\tilde{y} & \bar{n} \\
0 & 0 \\
8 & 0 \\
8 & \delta \\
8 & 8 \\
-1 & 0\end{array}$ \\
\hline 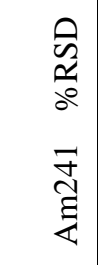 & 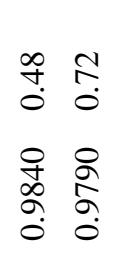 \\
\hline 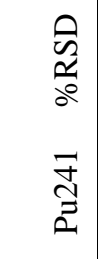 & 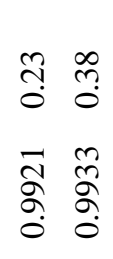 \\
\hline 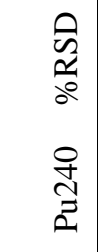 & 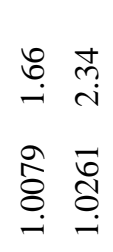 \\
\hline  & 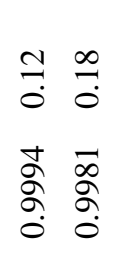 \\
\hline 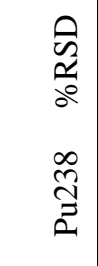 &  \\
\hline$\dot{\dot{z}} \stackrel{\Xi}{\Sigma}^{\mathscr{\Xi}}$ & $\cong \bumpeq$ \\
\hline 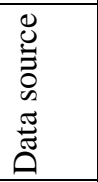 & 芯 \\
\hline
\end{tabular}




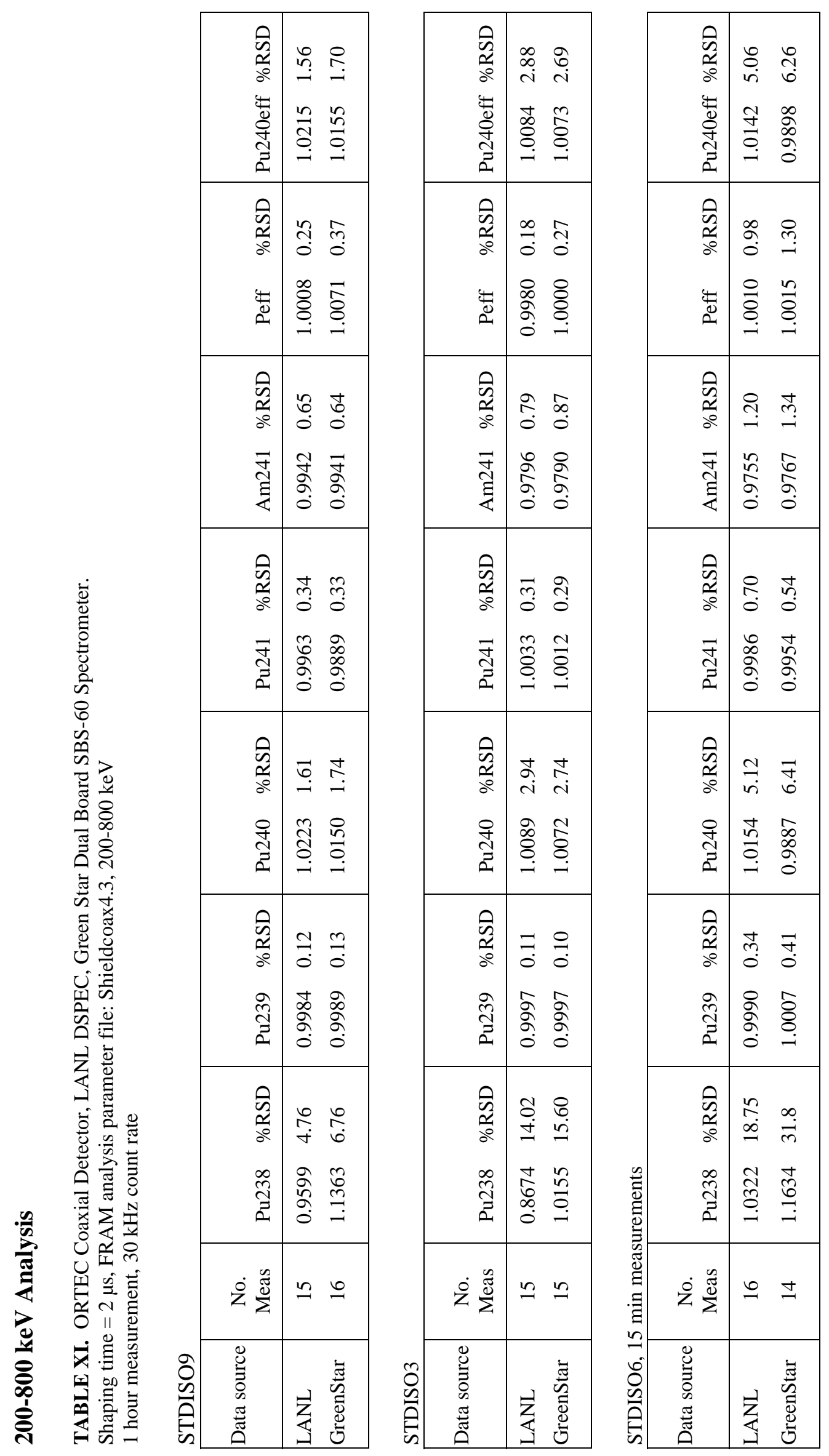




\section{SUMMARY}

We compared the Green Star SBS-60 spectrometer to three state-of-the-art, commercial US-made spectroscopy systems. Three Green Star SBS-60 systems were tested, one single board model and two experimental, dual board models. The SBS-60 systems exhibited significantly improved throughput compared to the SBS-50 tested two years ago. While the SBS-60 resolution and throughput were not as good as the three US systems (as might be expected from the portable, space-saving design of the SBS-60), they performed very well in acquiring plutonium sample spectra to be analyzed by the FRAM isotopic analysis software. The results from analysis in the $120-450 \mathrm{keV}$ region for data from both the single and dual board SBS-60 spectrometers was in agreement with analysis of data taken by the US systems and in agreement with accepted or passport values. Some data from the dual board Green Star systems gave results that were significantly biased for ${ }^{238} \mathrm{Pu}$ at $766 \mathrm{keV}$, both relative to the commercial US systems and also the accepted or passport values. This data collection problem is thought to arise from imperfect operation of the pileup rejector and is believed to be corrected in later models SBS-60s with the use of improved components. We did not test the single board system in the high-energy analysis mode, so we are unable to say if the problem appears in the single board system.

\section{REFERENCES}

1. T. E. Sampson, T. L. Cremers, Duc T. Vo, Y. P. Seldiakov, A. B. Dorin, M. V. Kondrashov, V. I. Timoshin, "LANL/Green Star Spectrometer Tests," Los Alamos National Laboratory document LA-UR-97-5026.

2. Thomas A. Kelley, Thomas E. Sampson, and Dorothea DeLapp, "PC/FRAM: Algorithms for the Gamma-ray Spectrometry Measurement of Plutonium Isotopic Composition," Los Alamos National Laboratory document LA-UR-95-3326.

3. T. E. Sampson, T. A. Kelley, T. L. Cremers, T. R. Konkel, and R. J. Friar, "PC/FRAM: New Capabilities for the Gamma-ray Spectrometry Measurement of Plutonium Isotopic Composition," Los Alamos National Laboratory document LA-UR-95-3287.

4. Thomas A. Kelley, Thomas E. Sampson, Ronald M. Keyser, and Timothy R. Twomey, "Recent Developments of LANL PC/FRAM Code," Los Alamos National Laboratory document LAUR-99-2010. 
This report has been reproduced directly from the best available copy. It is available electronically on the Web (http://www.doe.gov/bridge).

Copies are available for sale to U.S. Department of Energy employees and contractors from-

Office of Scientific and Technical Information

P.O. Box 62

Oak Ridge, TN 37831

(423) 576-8401

Copies are available for sale to the public from-

National Technical Information Service

U.S. Department of Commerce

5285 Port Royal Road

Springfield, VA 22616

(800) 553-6847 


\section{Los Alamos \\ NATIONAL LABORATORY \\ Los Alamos, New Mexico 87545}

